\title{
The Dynamics Between The Roots And The Wings: A Study On Innovative Organizations
}

\author{
Silvana Pereira de Aguiar \\ Getulio Vargas Foundation - FGV-EAESP \\ silvana.aguiar@fgv.br \\ Marcos Augusto de Vasconcellos \\ Getulio Vargas Foundation - FGV-EAESP \\ marcos.vasconcellos@fgv.br
}

\begin{abstract}
The present paper has the purpose of presenting the results of a research carried out to reach the following objectives: (1) to identify which objective and subjective factors are found at organizations that are systematically under innovation; (2) to present how those factors inter-relate; (3) to describe innovation processes within organizational dynamics. In order to develop this research, three organizations were chosen - Embraer, Promon and Odebrecht Construction - CNO. The conceptual framework used for field research was a combination of Innovation references with Hatch's Cultural Dynamics Model. By using Grounded Research with Content Analysis as the chosen methodologies, it was possible to identify factors that were present and enabled innovations in those corporations. The results herein presented are the identified factors and its relatedness within the organizational dynamics.
\end{abstract}

\section{INTRODUCTION}

This paper presents the results of a research that was carried out with the purpose of understanding the complexity of the innovation phenomenon, as well as innovation drivers by taking organizational and cultural dynamics into consideration. The intent was to understand which factors are present at organizations that systematically generated innovation. So, the research objectives were:

1. To identify the factors present - in subjective and objective manner - that enables innovation to occur systematically

2. To establish the relationship between those factors

3. To describe how innovation processes within organizational dynamics

4. To characterize an "innovative organization"

While reviewing reference material on innovation, it was clear that the literature available would not be enough for the understanding of the more intrinsic aspects of the organizational setting, its dy- namics and its culture. Such limitation results from the fact that the studies have stemmed from Economic Sciences, having been technology-and-product-focused, to reach administrative sciences only later. Even at this last stage, innovation studies did not show strong link with the developments taking place on organizational change and cultural dynamics. It could be perceived, then, that literature on innovation covers relevant issues, but leaves a gap - internal organizational dynamics. The aim was, then, to study those two angles in literature - of distinctive epistemological bases - which are not commonly addressed side by side. In order to reach an integrated perspective, the Cultural Dynamics Model (HATCH, 1993) was used, since it sponsors both subjective and objective organizational dynamics and its interactions.

Innovation stirs different mechanisms at organizations - not only economy-wise, but in management, organizational methods, technology, and processes - with social and cultural aspects standing out, since they address complex issues of social groups construction and survival, such as beliefs and fears when faced by uncertainty. 
Quite a number of issues came up as the work developed, and they were all included as investigation bases. Some of them were: How does innovation take place in cultural dynamics? What characterizes a culture that will sponsor innovation? What is understood by innovative organization? Which are the factors found in an innovative organization? How do those factors interact? Are there cause-consequence relations? Those questions tried to lead to detecting which organizational settings would sponsor and promote innovations in continuous and systematic fashion.

The questions in the previous paragraph raised the preliminary reflections that paved the way to define research objectives. The starting points were: (1) a literature review on innovation and organizational and culture dynamics; (2) Hatch's Cultural Dynamics model as the approach (HATCH,1993), since the authors believe it would help explain the innovation phenomenon in its objective and subjective aspects within the organizational context.

Complex challenges lie underneath the present research - to address innovations in its multiple factors, to search for their inter-relation, aware that each factor in itself would deserve a specific research project. The purpose of the present study, however, is to reach an understanding of the internal dynamics found in organizations under systematic innovation, rather than deepen the investigation of each factor isolatedly.

\section{LITERATURE REVIEW}

\section{Historical Background}

The first studies addressing innovation stemmed from Economic Sciences - The Austrian School and Joseph Schumpeter (1883-1950). Until then, traditional microeconomic analysis did not address the industry as a core object. Knowledge was seen as perfect, and no corporate action would not be necessary, neither any competitive process (HASENCLEVER, 1991).

Amid such debate, in 1934 Schumpeter pioneered the discussion on the relevance of innovation for economic development, pointing out the aspects corporations see themselves confronted by today. His focus addressed social and institutional issues and emphasized innovation as the source for development in capitalism. The role played by competition stimulated the search for new products, new technologies, and pushed organizations to build the skills and generate high quality, low cost products. Schumpeter made the distinction between "innovation" and "invention": an invention becomes relevant when it generates results, which turns it into an innovation.

The issues related to the role played by entrepreneurs in stimulating innovation investments also started being discussed by Schumpeter. His "creative destruction" concept takes place when an innovation promotes the obsolescence of existing technologies, thus bringing to the scenario the dynamics that is inherent to innovations.

Along the same line, the so-called Neo-Schumpeterian authors go further in their studies to say that innovations are associated to search, discovery, experimentation, development, imitation, and the placing of new products, new productive processes and new organizational techniques. Those authors point out the relevance of institutional (organizational) social dynamics as an impacting variable in technological change, but admit the difficulties faced when carrying out the epistemological unity between the economic and the institutional changes (FREEMAN, 1988).

The first gaps found in innovation studies can be detected here: how innovations actually take place in organizational dynamics and which are the difficulties that have to be faced while innovating.

\section{Innovations and Their Impact on Organizations}

A relevant topic in innovation studies is how (innovation) it is perceived. To be considered an innovation it must be perceived as such, which involves the following: Who recognizes that something is innovative, and then defines it as such? How does that become widely known in the social system, that is, the organization? The issue here is not restricted to the perception towards innovation, but rather how it is disseminated through the organizational community. To be considered an innovation, it must be perceived as such by the community it belongs to. Studies on innovations taken up by social systems have shown a time lapse for the perception on innovation to be actually installed. That will be of high relevance for research findings to be reported further on in the present paper (ROGERS, 2003).

The understanding of some attributes associated to innovations is also important, such as typology and its relevance. Many authors have devoted their studies to building distinctive innovation taxonomies.

(SCHUMPETER, 2000; GUNDLING, 2000;GAYNOR, 2002; LEIFER, 2002; Manual de Oslo, 1997) 
Innovations may be essentially classified according to their nature (Product, Process, Organizational, and Business Model Innovations) and comprehensiveness or size (from regular-basis improvements to radical and disruptive innovations). Christensen proposes a new approach, classifying Innovations as sustainers (trying to improve their company's performance at stabilized markets) and disruptive (those presenting a new value-added assumption) (CHRISTENSEN, 1997).

Innovations may also be considered as an organizational phenomena, which may be complex and relevant given their possible implications. Many authors, each one with their own approach, have studied the impact of innovations in organizational life. Others, have gone further, placing a need for new management requirements to address those innovation impacts. There seems to be a temporal relation between technologic and administrative innovations. In timeline studies, administrative innovations precede other nature of innovations, by generating the conditions or ambience, acting as context and catalyzer. One could, then, infer that the environment is relevant for innovation generation, (GAGLIARDI, 1986; ROGERS, 2003; EISENHARDT, 1997; CHRISTENSEN, 1997; MARCH, 1999; VAN DE VEN et al, 1999, 2000; GUNDLING, 2000; GAYNOR, 2002; TUSHMAN E MOORE, 1988; LAMPEL, 2000; WOOD, 2001, LEIFER, 2002).

A direct relationship between innovation relevance and comprehensiveness and its impact on organizational life and history can be established. The model that follows shows the relationship between the type of innovation (or change) and its impact, and how it interferes in organization stability. It shows three change categories (apparent, incremental, and revolutionary), which inspire some concepts to be developed later on in the present paper. The author creates those categories following the impact level generated by organizational change, as shown in the Figure 1 (GAGLIARDI, 1986):

Figure 1 - Gagliardi's Cultural Change Types

\section{Innovative Organizations}

Organizations face dilemmas while managing their operations, allocating resources, and defining how to handle current (operational) issues and strategic (future and innovation) challenges. The dilemmas stem from the fact that both current and strategic issues compete for the same resources.

In their day-to-day organizations focus on refining, improving, increasing efficiency, and carrying on their operational activities. Also, the day-to-day, a well-known domain, the rules have been set, the goals have been pre-defined - no explicit threats are presented. Somehow, organizations follow a sort of "automatic" flow. Their risk is to lag behind, but this is only perceived a posteriori. In their very nature, those initiatives are based on past experience.

On the other hand, the organization needs to be reformulated, redesigned, created, invented, and transformed in its own aspects. Such aspects result from survival needs and future growth needs. Therefore, the latter - future growth - is the challenge to be met. Innovations take place in a context of uncertainty, since this is the realm of the unknown - this is the field of innovations.

This nature of activity (innovation) requires strict planning and investment analysis, in order to survive and prove consecutive return and feasibility. Risk is easily perceived, since it is presented a priori.

The fight for resources is not balanced, since what has been established (day-to-day operation) is out of questioned, opposed to innovations that have to prove itself until there is some return (MARCH, 1999).

Additionally, the two natures of activities (the dayto-day and the innovations) require different management formats. Innovative contents carry uncertainties and fears - natural human feelings when facing the unknown. For that reason, organizations, as the innovations host, presents resistance and antagonistic environment. So, organizations deal with

\begin{tabular}{|l|l|l|l|}
\hline Type & Stability is Kept? & Generates Change? & Description of change \\
\hline Apparent & Yes & No & Superficial \\
\hline Incremental & Yes & Yes & Profound \\
\hline Revolutionary & No & Yes & Disruptive/Renovation \\
\hline
\end{tabular}

Source: Hatch (2004), in Gagliardi (1986) 
a conflict: on one hand, the desire and the need for change and for the new; on the other hand, the fear and even the "sabotage".

The competencies developed to meet known day-today reality may be what hinders the ability to see the new to come, the new demands. Innovations impact product life cycle in different ways, demand differential management forms, and must be properly linked to organizational strategy. Therefore, innovations demand well-managed, synchronic functional relationship so as to ensure proper management from idea generation to implementation, especially when innovations are radical and lead to disruption. Day-to-day activities do not present the same demands. (MARCH, 1999; VAN DE VEN, 1999, 2000; TUSHMAN and MOORE, 1988; TIDD, BESSANT, PAVITT, 2005, 2007).

One of the aspects that seem to be key to promote innovations - and that is directly related to management - is the way the work is organized. Management model - how people find freedom spaces in their work place to create and to take decisions about their work - seems to be a relevant component in the ability to innovate. The absence of those factors seems to restrict innovations. In that sense, work autonomy proves to be a relevant factor. The topic will be part of the propositions in the present research. (MARCH,1999; LAMPEL, 2000; TUSHMAN e MOORE, 1988; CHRISTENSEN, 1997; EISENHARDT, 1997, 1992; LEIFER, O'CONNOR, RICE, 2001, DAMANPOUR, 1996, O'REILLY III, TUSHMAN, 2004).

\section{Innovative Organizations and Culture Dynamics}

When searching for organizational and cultural dynamic concepts, the explanations on the relevance of organizational settings as "fertile ground" for innovations can be expanded. Without the proper understanding of the intrinsic component of internal organizational dynamics, it is not possible to comprehend the gaps left by the innovation literature.

The investigation on culture dynamic studies leads to a major author - Edgar Schein - who defined organizational culture in a dynamic way. In Schein's view, culture cannot be understood if detached from its dynamics, which means how culture is learned, transmitted, and transformed - all that makes culture an ongoing process of formation and change that is found in all aspects of human experience. Schein's model pointed out three layers in cultural dynam- ics: (1) artifacts (more apparent); (2) espoused values (intermediate level); (3) basic assumptions (more profound, and even unconscious). The interaction of those three levels leads to the dynamic understanding of the organizational system. (SCHEIN, 1984; MARTINS, TERBLANCHE, 2003).

Nonetheless, the Culture Dynamics Model advances if relative to Schein's model, since it embeds some key aspects: (1) cultural elements are no longer the core focus, and are replaced by interconnecting processes; (2) symbols are included, establishing its influence on organizational life; (3) relevance of interpretation process and sense making; (4) a direct relationship between subjective and objective aspects within the organization is established, thus allowing the inference of how the elements interact. Due to its complexity and comprehensiveness, this model was used as research reference for the present paper. $(\mathrm{HATCH}, 1993)$

\section{Figure 2 - Hatch's Cultural Dynamics Model - Source: Hatch (1993)}

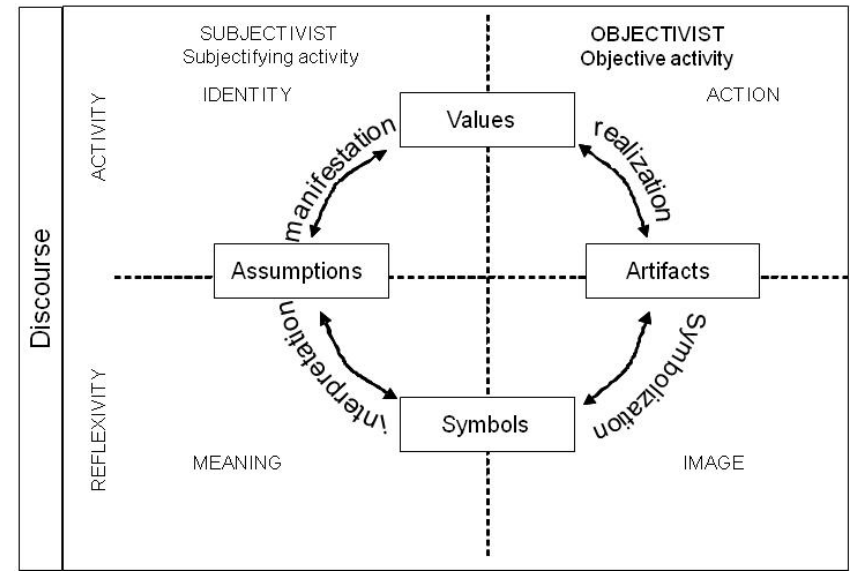

Since this model will be used as the framework in this research, it is important to have a brief description of the four processes involved in Cultural Dynamics: (1) Manifestation: it is the disclosure of essence, the process through which the Assumptions are translated into Values; (2) Realization: the process that articulates Values as expressed in Artifacts; to realize is to make something real, to bring to existence, therefore, changing expectations into social and material realities (artifacts); (3) Symbolization: translates artifacts into symbols, since it translates artifacts, in their literal form, into symbols, where meaning is expanded, and shared by organization members; (4) Interpretation: the subjective process through which people give meaning to something, some event, some experience, some artifact; interpretations are collective and 
highly influential in determining how that community thinks, acts, and works.

This framework leads to inferring how social order is construed through continuous negotiations between community members. Such interactions shape a common interpretation of reality, as well as a common work pattern. Social order is established through implicit understandings that are construed by shared experiences, which are interpreted and build patterns of meaning. Social actors perceive those interpretations as "objective reality", that is, through interpretation the members of a social group create patterns of meaning about their activities and about the world, therefore assuming that such patterns that have been created are separate from the interpretations that have produced them.

Organizations are formed by a group of people that share a number of beliefs, values, and assumptions that lead them to construe interpretations of their own actions and of the actions of others. Interpretation may be examined through stability, which is to say, the stability of a social group is related to a certain common, or habitual, mode of interpreting and sharing experiences. Daily sharing will lead to activity routine, and routines start going unnoticed. The repetition of such process leads the group to create their own ethos, they own, distinctive character, expressed through patterns and beliefs, by activities that are led by behavior norms, by a common language, and by other symbolic forms. All these factors together are the product of a common history. Even though many of the actors may leave the scene, the "character" tends to be kept. The aspects related to stability may be an obstacle to innovations. (BERGER E LUCKMANN, 1966; HATCH, 1993, 2004; SMIRCICH, ,, 1983; HERKOVITS, 1948).

Innovations are created in the organizational setting, defined as an "internal innovative context" (BARBIERI, 2003) following such dynamics and complexity, relating objective and subjective aspects of real life (BORINS, 2002). This explains the reason why the two aspects in literature have been reviewed.

\section{INITIAL CONSIDERATIONS}

The initial considerations that follow are the result of reflections on the literature reviewed, and are the foundation for research objectives construction. Some of those initial considerations are:

1. It seems everything in any organization is part of its "cultural stew"
2. If every organization is immersed in its "cultural stew", in its unique interpretive system, then every innovation may be a construction resulting from that culture;

3. Innovations seem to carry a transformation potential, since it carries the "new", it may alters the history, and impacts in organizational life;

4. Innovations seem to demand mobilization skills, since inertia and established patterns must be broken so that the "new" is implemented;

5. This combination of the "new" added to the organizational dynamics and its own idiosyncrasies, is likely to be the generator of the implementation difficulties addressed by innovation theoreticians;

6. By definition, artifacts are all perceptible, visible, and material realizations in the organization, such as: facilities, processes, products, technology, management model, systems, habits, behaviors, styles, language, communications, practices, rites, stories, ceremonies, etc. If all perceptible manifestations in an organization are artifacts, then we can candidly say that innovations are "new artifacts", provided they are perceived as such;

7. Therefore, innovations are not "things" or objects, but rather processes that emerge from ideas, are materialized by actions, and transformed into artifacts, which are symbolized and take up their meaning as innovations;

8. Once an innovation is implemented, it is no longer innovation, being then part of organizational routine and history. Innovations do not stay as such forever and ever; at times they seem to acquire the status of a symbol and a historical landmark.

The choice for Hatch's Cultural Dynamics Model was based on the need to find a theoretical model that would sponsor the understanding of how innovation processes within the organizational dynamics, and eventually the identification of the factors that are present in organizations under systematic innovation.

As a result of the rationale just presented, the research objectives have been outlined:

1. Identify the factors that are present in organizations under systematic innovation - of objective and subjective nature;

2. How those Factors inter-relate between each other; 
3. How innovation processes within organizational dynamics;

4. Characterization of an "innovative organization".

\section{RESEARCH}

\section{Methodology}

To meet all research requirements and for the Cultural Dynamics Model to be used, a research strategy was created by using Grounded Research (STRAUSS, 1998) associated to Content Analysis (BARDIN, 1977).

Grounded Research is an inductive methodology that builds a system of data collection and analysis to extract field content and put together a reference framework that enables the formulation of concepts and theories. The methodology allows the research of organizational dynamics and of social systems in their natural settings under subjective focus, since it does not generate rigid or prescriptive results. It also perfectly matches Content Analysis, thus sponsoring discourse analysis - of crucial importance for the study of social systems. Added to these methodologies there were used the following techniques: semi-structured individual interview, semistructured group interview and setting observations.

Organizations that presented the characteristics of an "innovative organization", at list from an outside perspective, were chosen for the research, since they were the ones with a history of systematic innovations. Three organizations were chosen not only based on their innovative characteristics, but also because their decision-making process is based in Brazil, thus making the research viable.

The chosen corporations were:

Embraer: one of the largest aircraft manufacturers in the world, by focusing on specific market segments with high growth potential in commercial, defense, and executive aviation. Has successfully developed products the filled niches not occupied by competitors, with high speed delivery standards and strong competitive ability to play in a global sense. Probably, one of the most globalized corporations in Brazil with operations all over the world. Currently, has approximately 20.000 (twenty thousand) employees.

Promon Engineering, Ltda: company that dedicates itself to design, integrate and implement complex solutions for key infrastructure sectors. The many drivers that enable its success are the mastery of engineering, project management, highly competent team and an unusual Management Style that has received all the prizes and public recognition in Brazil. Currently, has approximately 1,500 (on thousand and five hundred) employees.

Odebrecht Construction: company initiated in the northeast of Brazil, with its own managerial entrepreneur style (Odebrecht Entrepreneurial Technology TEO), very well structure, with books and an intense learning process throughout the corporation, which enabled an effective ongoing communication process. This management style seems to be the source of a entrepreneur based organization with clear results and solutions. Currently, has approximately 68,500 (sixty eight thousand and five hundred) employees and operations in seventeen countries.

The research took place considering different types of areas - staff, business and operations - and different hierarchical levels - from board of directors to operations.

Research propositions were construed for the proper use of the Cultural Dynamics Model. Those propositions guided field research, and were created for each process of the Culture Dynamic Model. Research propositions and corresponding results per company - as described - can be found in Figure 3.

Results

Figure 3: Research Propositions and Respective Results

\begin{tabular}{|c|c|c|c|}
\hline RESEARCH PROPOSITIONS & Promon & Embraer & Odebrecht \\
\hline $\begin{array}{l}\text { 1. a Hatch's CDNodd faciltabes the understanding } \\
\text { of lmovation wthin organzaton }\end{array}$ & C & c & c \\
\hline \multicolumn{4}{|l|}{ Manifestation Process } \\
\hline 2airmwatre organizations have strong alure & $C$ & C & c \\
\hline $\begin{array}{l}\text { 2blimovative urganizations hare assumplions } \\
\text { that squnsor / encourage innoration }\end{array}$ & C & C & $\mathrm{C}$ \\
\hline \multicolumn{4}{|l|}{ Realization Process } \\
\hline 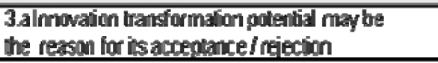 & $\mathbf{R}$ & $\boldsymbol{R}$ & $\mathbf{R}$ \\
\hline $\begin{array}{l}3 \text { blnnwalion transformalon potential may vary } \\
\text { along the rmocess }\end{array}$ & C & C & C \\
\hline $\begin{array}{l}\text { 3c Mlobilizaton is directly assuciated to } \\
\text { transfomation potental of the innoration }\end{array}$ & C & C & c \\
\hline $\begin{array}{l}\text { 3d Imwative onganizations hare simple stuctures } \\
\text { that squnsor autonumy and decision-malking }\end{array}$ & c & $\mathbf{P}$ & $c$ \\
\hline $\begin{array}{l}\text { 3.e Matagess encourage inovaliouts } \\
\text { at al levets }\end{array}$ & c & c & $c$ \\
\hline \multicolumn{4}{|l|}{ Symbolization Process } \\
\hline $\begin{array}{l}4 \text { alnnwation yill only be necognuzed } \\
\text { when umed into a smbol }\end{array}$ & C & C & c \\
\hline \multicolumn{4}{|l|}{5 Interpretation Process } \\
\hline $\begin{array}{l}\text { 5.almovative organizations intarprat falure, risk } \\
\text { and emurs as bearing }\end{array}$ & 6 & C & C \\
\hline $\begin{array}{l}\text { 5. Assumptions are added thenerer } \\
\text { an exbenal element is ascimiased }\end{array}$ & C & c & $\mathbf{I}$ \\
\hline
\end{tabular}

Legend: $\mathrm{C}=$ Confirmed; $\mathrm{R}=$ Reproved; I= Inconclusive; $\mathrm{P}=$ Partial 
As demonstrated, answers are consistent in their nature in each of the propositions. Except for 3.d and 5.b, where 2 organizations confirmed the propositions, all the others confirmed all propositions.

Due to methodology flexibility, others aspects were detected along research development. They have been named "research discoveries", and used the same framework (Figure 4). Discoveries were considered to be all cases in which at least two organizations presented the factor under research. It is important to consider that those discoveries emerged spontaneously during the research.

\section{Figure 4: Research Discoveries}

\begin{tabular}{|c|c|c|c|}
\hline FIGURE $\quad 3$ : DISCOVERIES & Promon & Embraer & Odebrech \\
\hline \multicolumn{4}{|l|}{ 6. Manifestation Process } \\
\hline 8. alnnovation is a assumplion & $\mathrm{Y}$ & $\mathrm{Y}$ & $\mathrm{Y}$ \\
\hline 6. b Freedom and Autonomy & $\dot{Y}$ & 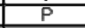 & $\bar{Y}$ \\
\hline \multicolumn{4}{|l|}{ 7. Realization Process } \\
\hline 7 a Cullure Sustainabiliv & $\bar{Y}$ & $\mathrm{~N}$ & $\mathbf{Y}$ \\
\hline $7 \mathrm{~b}$ Innovation Processin a free thinkingmode & $\gamma$ & $Y$ & $Y$ \\
\hline 7.CFast mobilizalion for innovation when aligned with Assumptions & $\mathrm{Y}$ & $\mathbf{Y}$ & $\mathrm{Y}$ \\
\hline $\begin{array}{l}\text { 7.dNegative Mobilization if inconsistent } \\
\text { with Assumptions }\end{array}$ & $\mathrm{P}$ & $\gamma$ & I \\
\hline 7.e Intensive andExten sive Communication & $\bar{Y}$ & $P$ & $\mathrm{Y}$ \\
\hline 7ffAnt-ingtia $\quad$ Mechanism & $\bar{Y}$ & $\mathrm{~N}$ & $Y$ \\
\hline \multicolumn{4}{|l|}{ 8. Symbolization Process } \\
\hline 8.a Symbolized Autifacts Support Innovation & $\mathbf{Y}$ & $Y$ & $\mathrm{Y}$ \\
\hline \multicolumn{4}{|l|}{ 9. Interpretation Process } \\
\hline 9.a Postive Self-Interpretation & $\bar{Y}$ & $\bar{Y}$ & $\bar{Y}$ \\
\hline $9 b$ Stronglies with the Organization & $\bar{Y}$ & $\bar{Y}$ & $\bar{Y}$ \\
\hline 9. Active Interpretation of the Environment & $\mathbf{Y}$ & $\mathrm{Y}$ & $\mathbf{Y}$ \\
\hline $\begin{array}{l}9 \mathrm{dCC} \text { CorentDiscourses, Aligned with } \\
\text { Assumptions }\end{array}$ & $\mathbf{Y}$ & $\mathrm{Y}$ & 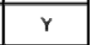 \\
\hline $\begin{array}{l}\text { 9.e FluentDiscourse Denoting Previous } \\
\text { Culture Con cepts }\end{array}$ & Y & $\mathbf{N}$ & Y \\
\hline
\end{tabular}

Legend: $\mathrm{Y}=$ Yes; $\mathrm{N}=\mathrm{No} ; \mathrm{I}=$ Inconclusive; $\mathrm{P}=$ Partial

\section{FACTORS PRESENT AT "INNOVATIVE ORGANIZATIONS"}

The factors that seems to be present at "innovative organizations", as a result of the research, will be described following the logic of Hatch's Cultural Dynamics Model.

\begin{tabular}{|c|}
\hline Manifestation Process \\
\hline $\begin{array}{l}\text { Factor } 1 \text { - Innovation as an Assumption } \\
\text { Innovating was found to be an assumption, being one strong aspect, coming from the foundation, the history in those } \\
\text { organizations. Innovating can be found to be deeply underlying the profound beliefs that shape how the organization } \\
\text { positions itself in its environment, by being active, identifying gaps, creating new realities (enacting). Abelief on the capability } \\
\text { of transforming the external environment. Therefore, innovating was found to be prestigious - whoever is important or } \\
\text { wants to grow in their career is involved in innovative projects, while being involved in non-innovative projects does not } \\
\text { add status. }\end{array}$ \\
\hline $\begin{array}{l}\text { Factor } 2 \text { - Strong Culture } \\
\text { Organizations with strong culture, with well sedimented and well disseminated values. This factor tends to ensure survival } \\
\text { since it helps face adversities in cohesion. One can infer that cultures that are not strong must face more difficulties in } \\
\text { promoting innovations due to the lack of cohesion and alignment. }\end{array}$ \\
\hline $\begin{array}{l}\text { Factor } 3 \text { - Freedom and Autonomy } \\
\text { When talking about their conditions for innovation respondents associated the values of freedom and autonomy. The word } \\
\text { freedom was brought up spontaneously in different situations: freedom to think, to have ideas and fight for them; freedom } \\
\text { of express opinion, freedom to suggest, to disagree, to "provoke", to decide, to act etc. As the topic was discussed further, } \\
\text { autonomy appeared to be a value without which, real innovative action could not be taken. }\end{array}$ \\
\hline
\end{tabular}

\section{Interpretation Process}

Factor 4 - Positive Self-interpretation

Self-interpretation is positive, as observed in self-perception phrases, as innovators and achievers, able to overcome obstacles and identify opportunities. A relationship between positive self-interpretation and innovation can be inferred.

Factor 5 - Strong ties

Strong ties expressed through statements - some of them emotional, others more rational but equally expressing affection and strong ties with the organization. When answering the question "What does the company mean to you?" many answers were: "It's my life", and many other emotional phrases and expressions. Strong ties on affective grounding basis might influence commitment level with the organization. 
Factor 6 - Interpreting Failure, Error, and Risk

Innovations are ideas, "novelties", things that have never existed before, do not carry clear solutions, and are highly experimenting. Therefore, error margins tend to be wider-ranging by dealing with the unknown, with failure having some probability. All three organizations under study faced the risk of extinction and did have failure experiences, having grown stronger after those experiences.

Factor 7 - Active Interpretation of the Environment

The way organization perceives its environment determines how it acts on it. Active and intrusive way of dealing and relating to the environment is observed in all three organizations researched.

The corporate action observed is translated by the creation of businesses niches in an active, competitive, and innovative mode.

Factor 8 - Discourse Coherence and Fluency

Discourse analysis showed language coherence both in expressions and in concepts. When associated to fluency, that coherence conveyed the feeling that the speakers were always the same, most likely as a result of a very conceptualized cultural elements that are communicated and disseminated in the respective communities. That was observed in two organizations under research.

Realization

Factor 9 - Culture Sustainability

A set of corporate activities kept by the organization to feed, strengthen, align, and disseminate culture with the purpose to preserve it, particularly in generation succession (found in two organizations).

Factor 10 - Organization and Management

The organizational structure is flexible, with mobility and adaptability, changing according to business needs, allowing autonomy at work. One may infer that innovations need such conditions to be generated and made viable (found in two cases).

Factor 11 - Innovation Process

The innovation process could be observed in two phases in the research: (1) Idea Generation Phase - the process is free, spontaneous, highly involving, highly discussed, with little formality, with freedom of opinion, and a lot of debate. At the end of this phase, internal sale takes place, demanding higher formality, since the idea must be defended and analyzed to be approved; risk seems to be addressed extensively, when the decision for project realization is made or not; (2) Development and Implementation Phase - development and implementation do not seem to be addressed separately; this phase also requires freedom, fluidity, and flexibility for necessary, continuous adjustments; it is, however, a more structured point in time, with organizational official approval, since resources are at stake and return on investment becomes a decision determinant.

Factor 12 - Transformation Potential

Defines the extent of what innovation may be or become; it may vary along innovation development - whether expanding or narrowing - possibly as a result of the interpretations and meanings attributed to innovation. Innovations typically carry strong symbolization, and shelter embedded transforming potential, thus leaving its marks in the organization history.

Factor 13 - Mobilization

A key factor for the success of the innovation process, since it is associated to engagement level, and therefore, to the readiness of resources availability and allocation - which in their turn will influence action quality standard. Mobilization may act as an indicator that cultural innovation may be accepted. That could sponsor the statement that innovation may be accepted or rejected depending on how it is perceived by the organizational community.

Factor 14 - Anti-Inertia Mechanism

A factor that is characterized as a structural dimension that evokes continuous mobility and system renovation, thus hindering aspects that promote inertia to be installed. The anti-inertia mechanism sponsors continuous organizational renovation. It was found in two organizations under research.

Factor 15 - Intensive and Extensive Communication

A factor that ensures the safe dissemination of culture and acts as a tool for cultural sustainability feasibility through people's involvement. Communication plays an active role in innovation process, particularly on idea dissemination, concept sharing, learning, and mobilization. 


\begin{tabular}{|c|}
\hline Symbolization Process \\
\hline $\begin{array}{l}\text { Factor } 16 \text { - Major Symbolized Artifacts } \\
\text { Some symbolized artifacts play a double role - culture sustainability and innovation driver. The present research observed } \\
\text { some artifacts that play a key role in constructing collective cohesion and amalgam. }\end{array}$ \\
\hline $\begin{array}{l}\text { Factor } 16 \text { a - Leaders as Symbols } \\
\text { Some top management representatives play the role of symbols - either due to some highly valued attribute in that specific } \\
\text { culture - such as vision, boldness, or competency - and become a constant symbolic reference, and even something like a } \\
\text { "guardian" of that culture through the personification of values. }\end{array}$ \\
\hline $\begin{array}{l}\text { Factor } 16 \text { - Innovation as Symbol } \\
\text { Innovations are artifacts that have been symbolized and interpreted as innovation in the domain of organizational meaning. } \\
\text { It seems that an artifact is denominated an innovation when it acquires some meaning in the social community and it has } \\
\text { been assimilated by an organization routine. From a liberal point of view, it seems contradictory. The present research } \\
\text { detected that something that is innovative seems to be a synonym for "good and accepted", thus belonging to the history of } \\
\text { the organization. Therefore, symbolization seems to emerge through innovation acceptance. }\end{array}$ \\
\hline
\end{tabular}

\section{THE INTER-RELATION OF FACTORS}

The sixteen factors are somehow inter-related. The authors intend to develop some logic explanation on those interactions.

1. Those factors are interdependent because they are present and distributed in the four processes of the Cultural Dynamics Model. Those processes follow a unique interaction logic within the model itself, and also with the relationship between the objective and subjective aspects of reality. It is important to consider that the four domains found in the Cultural Dynamics Model are deeply inter-related. They are different facets of the same reality.

2. The research allows the understanding that the organizations under study seem to shelter two factor categories, which is to say, researchers observed that factors can be of two natures: solid and fluid.

(2.1) Solidity Factors Field: this field puts together all the factors that bring cohesion and amalgam, and make up the basis for realizations. The subjective and objective factors put together, with their inter-relation logic, establish the solidity characteristics which in one given organization may act as the necessary foundation for survival and growth. In innovative organizations they may act as the ground basis when facing challenging situations emerging from innovations through their transformation potential that requires strong community cohesion. Cultural solidity showed to be a key attribute in the organizations under research: it seems to have been crucial for company resistance and firmness at harsh times. The attribute, in itself, does not seem to determine whether the organization is innovative, since solidity may imply rigidity, typically found in some traditional organizations that are solid institutions.

(2.2) Fluidity Factors Field: this field brings together all the factors that promote the ability to create, to move, and to pursue active search for solutions along new pathways, thus constituting its innovative force. The Fluidity Factors Field seems to be proportional to the amount and intensity of the factors that are responsible for organizational creativity and mobility skills. These factors, added by their inter-relationships, establish the creativity and mobility skills that are necessary to innovation. At organizations under systematic innovation those factors seem to promote the naturalness and spontaneity of the creative processes that help face challenging situations and generate innovations with high transformation potential.

Figure 5 - Correlation between factors in an innovative setting

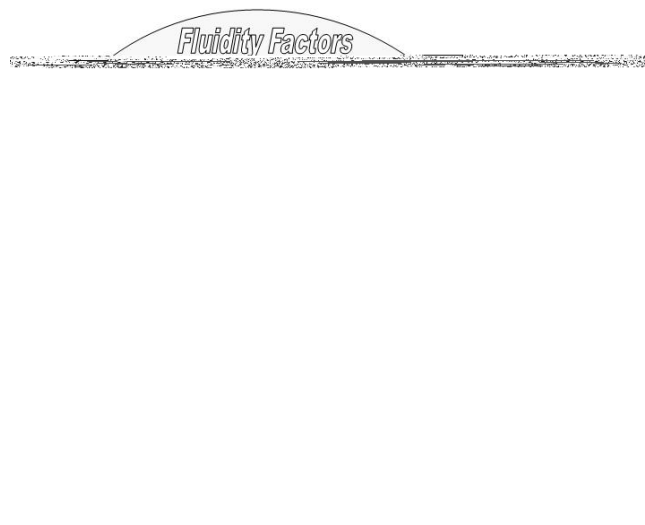


When associated, the attributes solidity and fluidity seem to indicate a balance between the ability to have internal sustainability and the ability to move. In the cases under study, fluidity factors were the basis for the ability to innovate. That does not mean there is a priority between the fields, but rather that there is a balance, or a complementary composition.

In Figure 6 the factors in each of the processes in Culture Dynamics may be visualized, forming two concentric circles. In the internal circle the factors associated to solidity, and in the external circle, those associated to fluidity.

\section{Figure 6 - Factors per Cultural Dynamics Process}

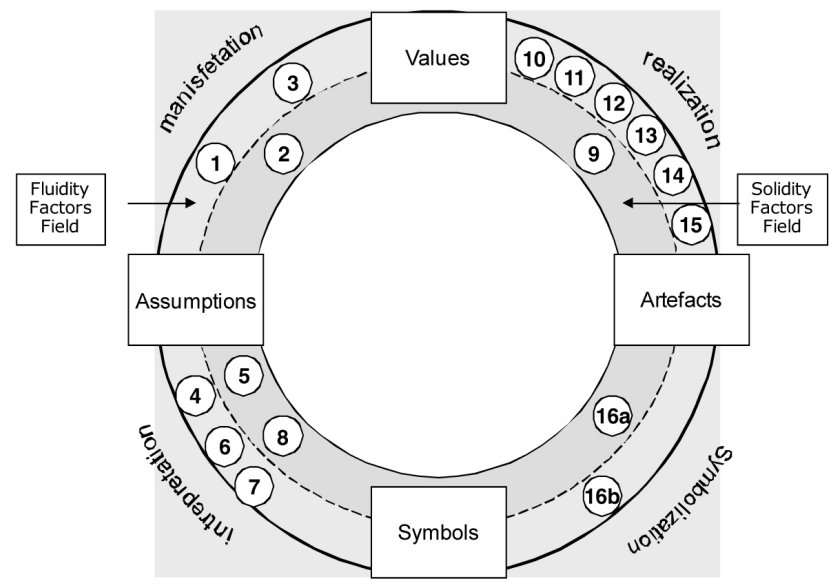

Factors: 1. Innovate is an Assumption; 2. Strong Culture; 3. Freedom and Autonomy; 4. Positive Self-Interpretation; 5. Strong Link; 6. Interpretation of Failure, Error and Risk; 7. Interpretation of Setting; 8. Coherence and Fluency in Discourse; 9. Culture Sustainability; 10. Organization and Management; 11. Innovation Process; 12. Transformation Potential; 13. Mobilization; 14. AntiInertia Mechanism; 15. Intensive and Extensive Communication; 16. Major Symbolizes Artifacts.

Based on field characterization as presented above, alternatives can be drawn as to how they relate, as seen in Figure 7.

Figure 7-Relationship between Solidity and Fluid ity

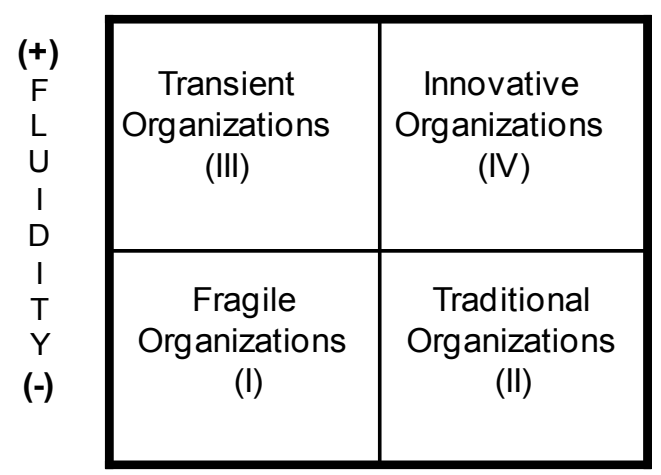

$(-)$ SOLIDITY
It is important to point out that the four quadrants do not stand for stagnant typologies. Organizations may migrate from one quadrant to the other, depending on the point in time, their circumstances, and, above all, how they are being managed. These are not categories, but dynamic states which may change.

1. Fragile Organizations: due to their absence or low intensity of solidity and fluidity factors, those organizations that may face difficulties in creating working conditions. They may be new organizations, still without a history or a body of minimal experience level to generate alliances. One can also think about organizations with conflicting sub-cultures that hinder the constitution and the balancing of solidity and fluidity factors.

2. Traditional Organizations: those with strong solidity factors, with assumptions and values strongly sedimented. They may be organizations in stable markets, government institutions, religious institutions, etc. They are expected to present strong stability mechanisms.

3. Transient Organizations: those with high fluidity and low solidity level. They may be organizations that start out with high creative content, as the IT (information technology) organizations that emerged in the Internet "bubble". They may acquire a different configuration, and may migrate to another quadrant, according to their evolution.

4. Innovative Organizations: those with full solidity and fluidity factors, in a balanced composition.

\section{FINAL CONCLUSIONS}

The present research tried to identify the characteristics and factors presented by "Innovative Organizations", turning their environment, or their setting, into fertile ground for innovations. We can now introduce a more wide-reaching definition of an innovative organization:

The innovative organization presents widereaching solidity and fluidity factors, leads to systematic, continuous innovation with high transformation potential, to high mobilization operations, and to the realization of artifacts that will tend to be symbolized and interpreted both internally and externally as innovations. An organization that is able to import and to 
assimilate external innovations, re-aligning values and adding new aspects to its assumptions. An organization that associates the ability to move with its internal strength to deal with adversities.

The present research has tried to integrate types of knowledge that have not been put side by side until this point in time, thus sponsoring a vision of innovation through aspects of cultural dynamics and organizational change by associating distinctive disciplines. The association of the foundation of those types of knowledge helped explain the difficulties innovations are faced with at organizations when encountering internal dynamic aspects.

Considering the organizational context, a relationship was established between the impact generated by innovation - innovation transformation potential - and organizational internal dynamics. Such approach helped the realization that innovations require management to be performed distinctively from its day-to-day.

This organizational context led to the core of the present research work: the sixteen factors found in an innovative organization as well as their interrelationships, and the definition of an innovative organization. Identifying the factors found in the organizations under research led to identifying some relationships among them:

1. A relationship of inter-dependence, since they can be found in the four processes in the Cultural Dynamics Model, with those processes following their very own interaction logic.

2. A relationship between the subjective and objective aspects of the organization: (1) subjective aspects seem to be an invisible source from which all visible aspects (artifacts) emerge at the organization; (2) as a result, objective aspects also sponsor impact on subjective aspects.

3. A relationship between solidity factors (roots) and fluidity aspects (winds), as discussed previously.

It is important to understand that organizations are "whole" phenomena, where the many aspects establish intrinsic relationship. That is where the present research presents innovation through the vision of innovative organizations - organizations that shelter fertile grounds in many of their aspects. The authors believe that those organizations not having these characteristics will not generate innovations in consistent and systematic fashion.

Therefore, as complex social systems organizations may be understood from the following metaphor: as in nature, strong, leafy trees are based on deep roots, and birds need wings to fly: likewise, innovative organizations need both roots and wings.

\section{REFERENCES}

AGUIAR, Silvana Marques dos Santos Pereira de. A Dinâmica entre raízes e asas: um estudo sobre organizações inovadoras. São Paulo, Silvana Marques dos Santos Pereira de Aguiar, 2004

AHMED, Pervaizk. Culture and Climate for Innovation. European Journal of Innov. Management, Vol. 1, number 1, pp 30-43, 1998

BARBIERI, Carlos José (org.). Organizações inovadoras: estudos e casos brasileiros. Rio de Janeiro: Editora FGV, 2003.

BARDIN, Laurence. Análise de conteúdo. Lisboa: Edições 70, 1995. (Primeira edição francesa data de 1977).

BERGER, Peter L.; LUCKMANN, Thomas. A construção social da realidade: tratado de sociologia do conhecimento. 22. ed. Petrópolis: Vozes, 2002. (Primeira edição alemã data de 1966).

BESSANT, John and TIDD, Joe. Inovação e Empreendedorismo. Tradução Elizamari Rodrigues Becker et all, Porto Alegre: Bookman, 2009

BORINS, Sandford. Leadership and innovation in the public sector. Leadership \& Organization Development Journal, 23/8, 467476, 2002

CHRISTENSEN, Clayton M. The innovator's dilemma: when new technologies cause great firms to fail. Boston: HBS Press, 1997.

DAMANPOUR, Fariborz. Organizational complexity and innovation: Developing and testing multiple contingency models. Management Science Linthicum, Vol. 42, n.5, p. 693, May 1996

EISENHARDT, Kathleen M.; BROWN, Shona L. The art of continuous change: linking complexity theory and time-paced evolution in relentlessly shifting organizations. Administrative Science Quarterly, Ithaca, v. 42, n. 1, p. 1-34, Mar. 1997.

EISENHARDT, Kathleen M. and ZBARACKI, Mark J. Strategic Decision Making, Department of Industrial Engineering and Engineering Management, Stanford University, Stanford, California, U.S.A. Strategic Management Journal, Vol. 13, 1737,1992

FREEMAN, Christopher. Introduction. In: DOSI, Giovanni et al. (eds) Technical change and economic theory. London: Pinter Publishers, 1988. p. 1-8.

GAGLIARDI, Pasquale. The creation and change of organizational cultures: a conceptual framework. Organization Studies, Berlin, v. 7, n. 2, p. 117-134, 1986.

GAYNOR, Gerard H. Innovation by design: what it takes to keep your company on the cutting edge. New York: Amacon, 2002. 
GUNDLING, Ernest. The 3M way to innovation: balancing people and profit. Tokyo: Kodansha International, 2000

HASENCLEVER, Lia. Estrutura industrial e mudança tecnológica: problemas teóricos. Rio de Janeiro: FEA-UFRJ, 1991.

HATCH, Mary Jo. Dynamics in organizational culture. New York: Oxford University Press. 2004. (no prelo)

HATCH, Mary Jo. The dynamics of organization culture. The Academy of Management Review, v. 18, n. 4, p. 657-693, Oct. 1993.

HERKOVITS, Melville J. Man and his works. New York: Knopf, 1948.

LAMPEL, Joseph. Product demonstrations and path creation of technological change. United Kingdom: University of Nottingham, 2000.

LEIFER, Richard. A implementação de inovação radical em empresas maduras. RAE: Revista de Administração de Empresas, São Paulo, v. 42, n. 2, p. 17, Abr./Jun. 2002.

LEIFER, Richard; O'CONNOR, Gina Colarelli; RICE, Mark. Implementing radical innovation in mature firms: The role of hubs. The Academy of Management Executive, Vol. 15, n.3, pg 102, ABI/INFORM Global, Aug 2001

MARCH, James G. The pursuit of organizational intelligence. Malden, MA: Blackwell Business, 1999.

MARTINS, E.C. and TERBLANCHE, F.. Building organizational culture that stimulates creativity and innovation. Europen Journal of Innovation Management, Vol. 6, n.1, pp. 64-74, 2003

ORGANIZATION FOR ECONOMIC CO-OPERATION AND DEVELOPMENT. Oslo Manual: proposed guidelines for collecting and interpreting technological innovation data. Paris, 1997

O'REILLY III, Charles A. and TUSHMAN, Michael L.. The Ambidetrous Organization. Harvard Business Review, abr 2004

ROGERS, Everett M. Diffusion of innovations. 5.ed. New York: Free Press, 2003.

SCHEIN, Edgar H. Coming to a new awareness of organizational culture. Sloan Management Review, Cambridge, v. 25, n. 2, p. 3-16, Winter 1984.

SCHUMPETER, J. Entrepreneurship as innovation. In: SWEDBERG, Richard (Ed.). Entrepreneurship: the social science view. Oxford: Oxford University Press, 2000. Cap. 2, p. 51-75.

SMIRCICH, Linda. Organizacional culture. Administrative Science Quarterly, v. 28, n. 3, p. 339-358, Sep. 1983b.

STRAUSS, Anselm; CORBIN, Juliet. Basics of qualitative research: techniques and procedures for developing grounded theory. London: Sage Publications, 1998.

TIDD, Joe; BESSANT, John; PAVITT, Keith. Gestão da Inovação; tradução Elizamari Rodrigues Becker et all, 3.ed., Porto Alegre: Bookman, 2008

TUSHMAN, Michel L.; MOORE, William L. Readings in the management of innovation. 2. ed. New York: Harper Business, 1988.

VAN DE VEN, Andrew H. et al. The innovation journey. New York: Oxford, 1999.

VAN DE VEN, Andrew H. et al. Research on the management of innovation: the Minnesota studies. New York: Oxford, 2000

WOOD JÚNIOR, Thomaz. Organizações espetaculares. Rio de Janeiro: Editora FGV, 2001

\section{AUTHOR'S BIOGRAPHY}

Silvana Pereira de Aguiar is $\mathrm{PhD}$ on Business Administration, major in Innovation and Corporate Transformation. Professor at "Fundação Getúlio Vargas" Business School is also Founder of Innovation Forum - FGV - EAESP. Partner at "ANTAR Processos de Transformação", a consulting business enterprise, with seventeen years of experience with focus on organizational transformation, culture and innovation, having as customers Embraer, Ford, Copesul, Odebrecht, Braskem, BCP Telefonia Celular, Cargill, Camargo Corrêa, IG, Santander, Telefônica, Petrobrás, Unilever, Nestlé, CTEEP, Monsanto. Former executive of the Brazilian branches of Bayer and Monsanto.

Marcos Augusto de Vasconcellos is a doctor in Business Administration by FGV-EAESP. He is a titular professor of the Production and Operations Management Department from FGV-EAESP since 1986. He was Academic Dean of FGV-EAESP from 2003 to 2007. Since 1999 is the coordinator of the FGV-EAESP Innovation Forum. 